\title{
The variable effects of angiotensin converting enzyme inhibition on myocardial ischaemia in chronic stable angina
}

\author{
J SIMON R GIBBS, PETER A CREAN, LORNA MOCKUS, \\ CHRISTINE WRIGHT, GEORGE C SUTTON, * KIM M FOX \\ From the National Heart Hospital, London and ${ }^{\star}$ Hillingdon Hospital, Uxbridge, Middlesex
}

SUMMARY The effect of angiotensin converting enzyme inhibition on myocardial ischaemia was studied in 12 normotensive patients with chronic stable angina and exercise induced ST segment depression. The study was randomised, double blind, placebo controlled, and crossover with treatment periods of two weeks. Enalapril was used to inhibit angiotensin converting enzyme. Assessment was by angina diaries and maximum symptom limited treadmill exercise tests. The results for the whole group showed a significant reduction in systolic blood pressure at rest and at peak exercise. Mean total exercise duration was $466 \mathrm{~s}$ (95\% confidence interval 406 to 525) when the patients were taking placebo and 509 s (436 to 583) when they were taking enalapril. Four patients prolonged their total exercise time (mean 450 to mean $591 \mathrm{~s}$ ) by more than $20 \%$. Two patients, however, developed ischaemia earlier on exercise and reduced their total exercise duration (mean 490 to mean $390 \mathrm{~s}$ ).

Although angiotensin converting enzyme inhibition tended to reduce myocardial ischaemia in the group as a whole, some patients improved while others deteriorated. Thus the effects of enalapril are variable and this may have important implications when enalapril is used to treat heart failure in patients with underlying severe ischaemic heart disease.

Angiotensin converting enzyme inhibition reduces left ventricular diastolic pressure, aortic systolic pressure, and sympathetic drive. ${ }^{1-3}$ Such effects should reduce myocardial work and oxygen consumption and hence may be beneficial to patients with angina. Angiotensin converting enzyme inhibitors are used successfully to treat coexisting hypertension and heart failure in patients with coronary artery disease although their actual effect on myocardial ischaemia is not defined.

We tested the hypothesis that angiotensin converting enzyme inhibition reduces myocardial ischaemia in patients with chronic stable angina.

\section{Patients and methods}

Twelve patients (11 men and one woman; mean age 55 years (range $46-70$ years)) with chronic stable

Requests for reprints to Dr J Simon R Gibbs, National Heart Hospital, Westmoreland Street, London W1M 8BA.

Accepted for publication 2 February 1989 angina that had not increased in frequency or duration in the preceding three months were entered into the trial. The frequency of their angina varied from one attack per month to five attacks per day. All patients were normotensive, had a positive exercise test with $>0.1 \mathrm{mV}$ linear or downsloping ST segment depression, normal electrolytes, and normal renal function. Three patients had sustained a previous myocardial infarction and two other patients had undergone coronary artery bypass grafting ten years before.

The protocol was approved by the National Heart and Chest Hospitals ethics committee and written informed consent for the trial was obtained from all patients.

\section{STUDY DESIGN}

We investigated the anti-ischaemic effect of 10-20 $\mathrm{mg}$ of enalapril once daily in a randomised, double blind, placebo controlled, crossover study with two treatment periods of two weeks each. All drug treatment apart from glyceryl trinitrate was stopped. After a one week washout period on glyceryl trini- 
trate alone, the patients were randomised to receive either enalapril $10 \mathrm{mg}$ once a day for one week increasing to $20 \mathrm{mg}$ once a day for a further week, or matching placebo. After a one week washout period patients were crossed over to receive either placebo or enalapril for a further treatment period of two weeks. The dose of enalapril or matching placebo was not increased after the first week of treatment if the resting systolic blood pressure was $<100 \mathrm{~mm} \mathrm{Hg}$, if the patient was experiencing side effects, or the patient had become symptom free.

Patients were assessed by angina diaries and symptom limited treadmill exercise tests with a modified Bruce protocol ${ }^{5}$ of three minute stages. The treadmill exercise tests were performed 1-5 hours after drug administration, at the same time of day for each patient, on the last day of each treatment period.

A 12 lead electrocardiogram was recorded before exercise, every minute during exercise, and for five minutes after stopping. Blood pressure was recorded with a cuff before exercise and at every three minutes during exercise. The patients were asked to report when their angina started and when it worsened. Exercise was stopped by disabling angina. The electrocardiograms were analysed to determine heart rate and time to $1 \mathrm{mV}$ ST segment depression. Total exercise time was also recorded. Serum concentrations of enalaprilat were measured by radioimmunoassay of blood samples taken immediately after exercise testing. ${ }^{6}$

\section{STATISTICAL ANALYSIS}

All data were analysed without knowledge of the patients' treatment. Measurements were made of the time to onset of $0.1 \mathrm{mV} \mathrm{ST} \mathrm{segment} \mathrm{depression} \mathrm{and}$ total exercise duration; and of heart rate, blood pressure, and rate-pressure product at rest, at $0.1 \mathrm{mV}$ ST segment depression, and at peak exercise.

For statistical testing, a Hills and Armitage crossover analysis was performed. The differences between systolic blood pressure measurements were compared by a Student's $t$ test. The results of exercise testing were analysed to determine the differences for each patient in exercise time and time to $1 \mathrm{mV}$ ST segment depression between placebo and enalapril.

\section{Results}

All 12 patients completed the study. As a result of an error in randomisation, seven patients received enalapril and five patients received placebo as their first treatment. A non-orthogonal analysis of variance showed that there had been no treatment effect, period effect, or treatment period interaction. The magnitude of the treatment effect on the total exercise time was $31 \mathrm{~s}(95 \%$ confidence interval from -46 to $+109 \mathrm{~s}$ ), and on the time to $1 \mathrm{mV} \mathrm{ST}$ depression was $51 \mathrm{~s}(95 \%$ confidence interval -33 to $+135 \mathrm{~s}$ ).

During the enalapril period, three patients (numbers $2,5,11$ ) did not have the dose of enalapril increased beyond $10 \mathrm{mg}$ daily because systolic blood pressure was already $<100 \mathrm{~mm} \mathrm{Hg}$. No patient on placebo had a significant reduction in systolic blood pressure.

\section{HAEMODYNAMIC CHANGES}

Systolic blood pressure at rest fell from 134 (16) (1 SD) on placebo to 118 (15) $\mathrm{mm} \mathrm{Hg}$ and at peak exercise from 165 (30) to $146(27) \mathrm{mm} \mathrm{Hg}$ (p < 0.05) (fig 1). Similarly, the rate-pressure product at rest fell from 10329 on placebo to 9487 on enalapril and at peak exercise from 20259 to 17930 (p < 0.05). Heart rate at rest and peak exercise was unaffected by enalapril.

\section{MYOCARDIAL ISCHAEMIA}

For the whole group, total exercise duration increased from $466 \mathrm{~s}(95 \%$ confidence interval 406 to 525 ) during placebo to 509 s (436 to 583) during enalapril (fig 2). The difference between the sample mean total exercise duration on enalapril and placebo was $43 \mathrm{~s}(95 \%$ confidence interval -55 to $+142 \mathrm{~s})$; the $t$ test statistic was 2.07 with 11 degrees of freedom. Exercise duration $0 \cdot 1 \mathrm{mV}$ ST segment depression rose from $345 \mathrm{~s}(95 \% \mathrm{CI} 300$ to 390$)$ on placebo to $387 \mathrm{~s}(95 \%$ CI 322 to 453$)$ during enalapril (fig 3). The difference between the sample mean exercise duration to $1 \mathrm{mV} \mathrm{ST}$ depression was $42 \mathrm{~s}$ $(95 \% \mathrm{CI}-48$ to $+134 \mathrm{~s})$; the $t$ test statistic was 2.07 with 11 degrees of freedom.

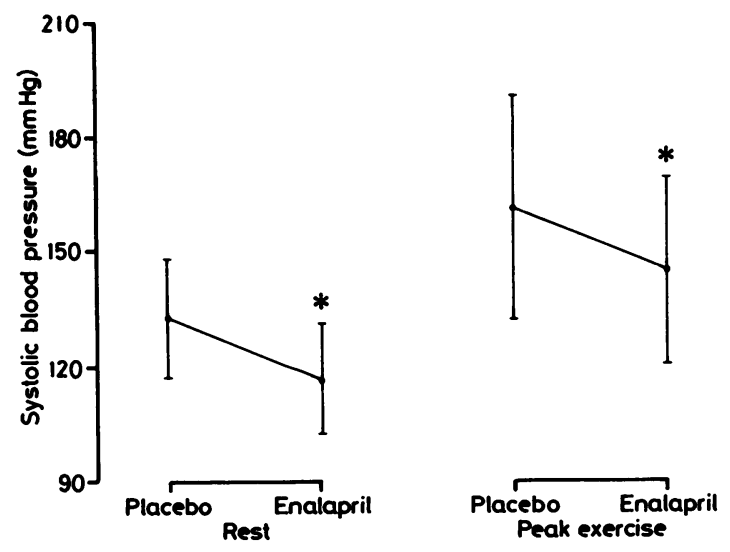

Fig 1 Systolic blood pressure at rest and at maximum exercise on placebo and enalapril Mean (1SD) is shown. ${ }^{\star} p<0.05$. 

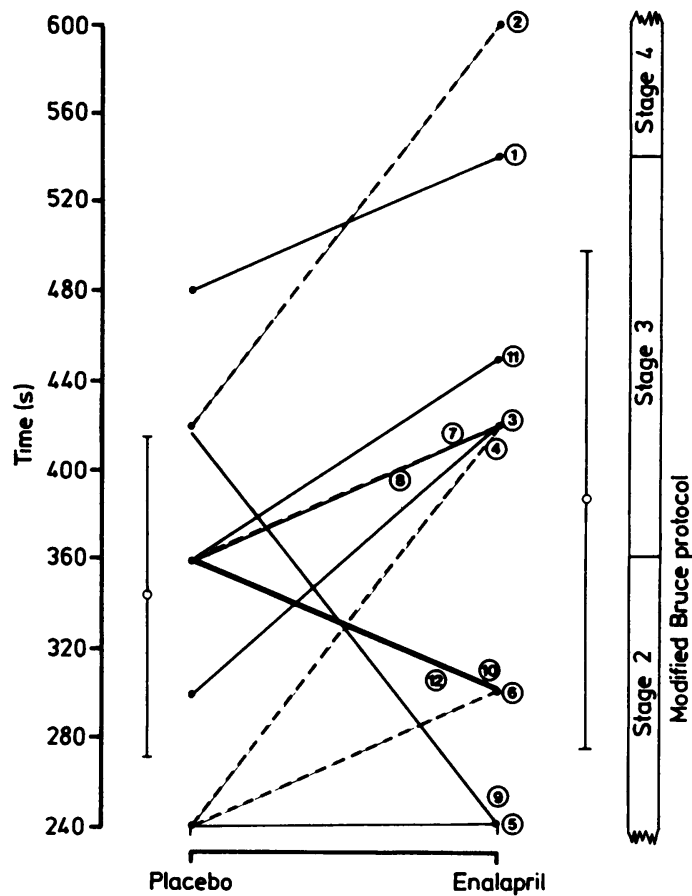

Fig 2 Total treadmill exercise duration before and during treatment with enalapril. Dotted lines indicate the four patients with improvement of total exercise duration by more than 20\%. Mean (1 SD) given for whole group. Individual patients are numbered.

Four patients (numbers 2, 4, 6, and 7: shown as dotted lines in figs 2 and 3 ) had an increase in total exercise time of more than $20 \%$ on enalapril compared with placebo (fig 4).

Two patients (numbers 9,10 ) showed reduction of both their total exercise time (fig 4) and the time to $0.1 \mathrm{mV}$ ST segment depression (fig 5). One of these patients (number 9) also had considerable reduction in systolic blood pressure at rest from 150 to 110 $\mathrm{mm} \mathrm{Hg}$ (mean fall for group $16 \mathrm{~mm} \mathrm{Hg}$ ). The fall in the peak exercise blood pressure in this patient did not differ from the group mean.

There were no clinical differences in the characteristics of our patients that determined the effect of enalapril on myocardial ischaemia.

\section{SYMPTOMS}

The frequency of angina attacks and glyceryl trinitrate consumed were not altered by enalapril. Three out of the four patients whose exercise times improved considerably, also had a reduction in the mean number of angina attacks on enalapril from 21 to 11 attacks per week and a reduction in glyceryl trinitrate consumption from 11 to nine tablets per

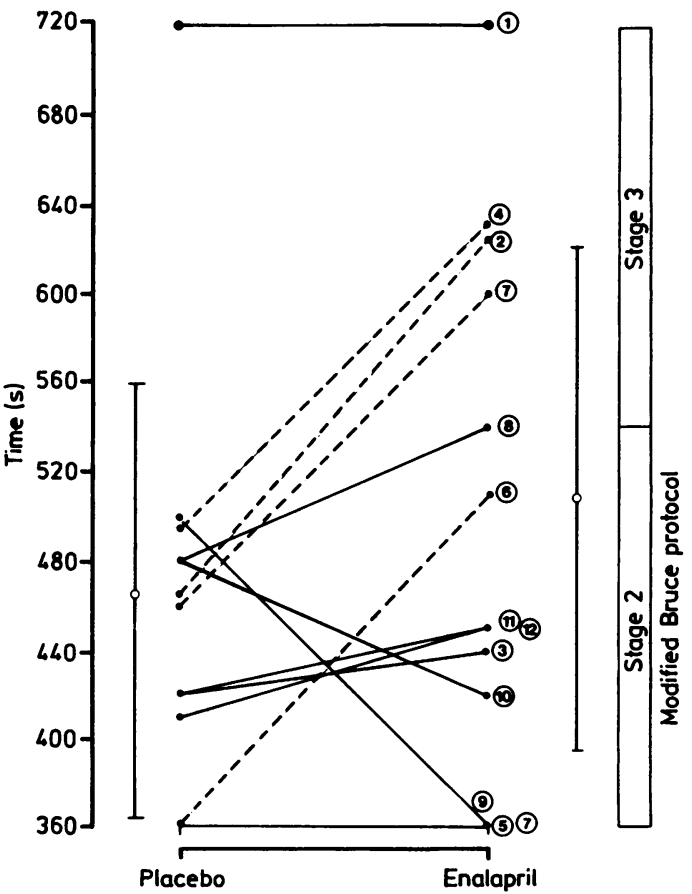

Fig 3 Duration of treadmill exercise to $1 \mathrm{mV} S T$ segment depression. Dotted lines indicate the four patients whose total exercise duration improved considerably. Mean (1 SD)

given for the whole group. Individual patients are numbered.

week. The fourth patient was unaffected, having one angina attack and consuming one glyceryl trinitrate tablet per week on both placebo and enalapril. The two patients who had a deterioration in both total exercise duration and time to $1 \mathrm{mV}$ ST segment depression had a rise in angina attacks on enalapril from 12.5 to 16.5 per week and glyceryl trinitrate consumption rose from 11 to 13.5 tablets per week.

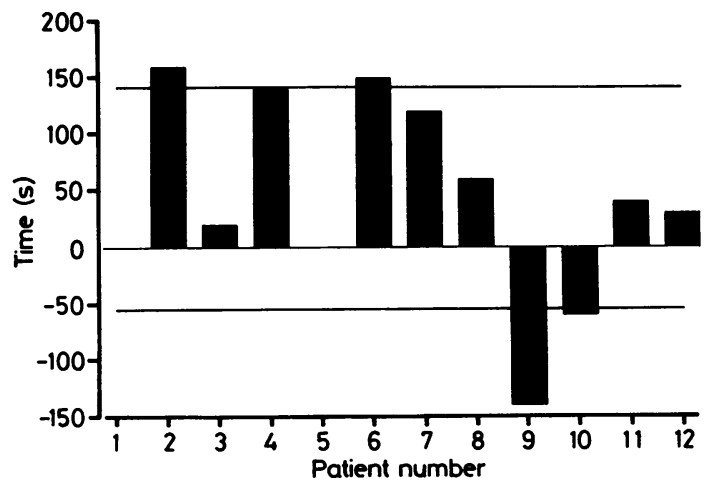

Fig 4 Change in total exercise time during treatment with enalapril compared with placebo. The results are shown for individual patients. 95\% confidence interval is shown. 


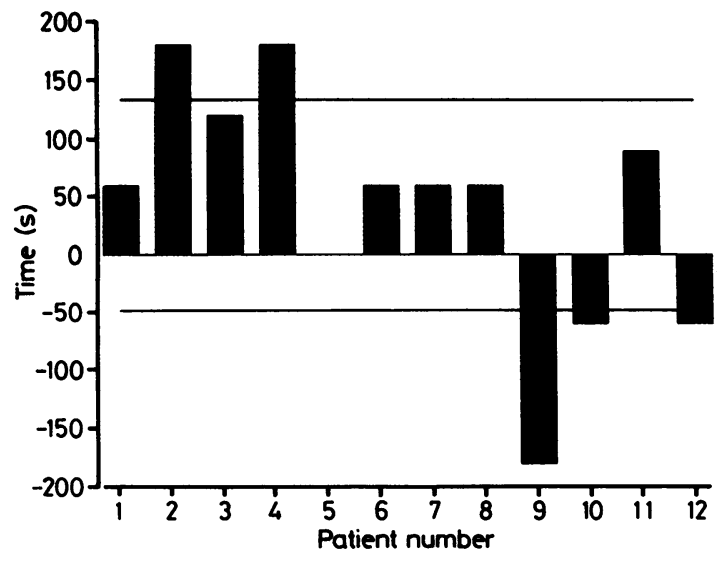

Fig 5 Change in time to $1 \mathrm{~mm} S T$ segment depression during treatment with enalapril compared with placebo. The results are shown for individual patients. The 95\% confidence interval is shown.

\section{DRUG CONCENTRATIONS}

Serum concentrations of enalaprilat 2-5 hours after patients had taken enalapril ranged from 24 to $90 \mathrm{ng} /$ $\mathrm{ml}$ (mean 56). The activity of angiotensin converting enzyme is almost completely inhibited by a concentration of $10 \mathrm{ng} / \mathrm{ml}^{6}$

\section{LABORATORY VALUES}

Laboratory values for routine haematological and biochemical variables remained within the normal ranges for all patients during the study. Weight was unchanged during the study (enalapril $77.5(13.8) \mathrm{kg}$, placebo $78.0(13 \cdot 5) \mathrm{kg}$ ).

\section{SIDE EFFECTS}

When taking enalapril two patients experienced mild disorientation that subsided spontaneously. Treatment was not interrupted.

\section{Discussion}

Enalapril is a prodrug that is hydrolysed to enalaprilat, its active metabolite. ${ }^{7}$ This angiotensin converting enzyme inhibitor reduces plasma concentrations of angiotensin II and aldosterone and this is associated with a rise in plasma renin activity. During the treatment phase of this randomised double blind study we saw a fall in blood pressure without reflex tachycardia as was seen in many other studies. Consequently, there was a fall in the rate pressure product in all of the patients. The indices of myocardial ischaemia (total exercise test and time to 1 $\mathrm{mV}$ ST segment depression) tended to improve in the group as a whole. Interestingly, four patients seemed to show a considerable improvement in these variables (increasing their total exercise time by more than $20 \%$ ) and two patients deteriorated. There was no overall change in episodes of angina or number of glyceryl trinitrate tablets consumed during the enalapril phase as compared with placebo. This is not surprising, however, as these patients had mild symptoms and did not require much glyceryl trinitrate even during the placebo phase. Why then, did the myocardial ischaemia seem to improve in some patients and deteriorate in others taking enalapril?

There are several mechanisms by which angiotensin converting enzyme inhibition might ameliorate myocardial ischaemia. Firstly, in normotensive individuals enalapril reduces blood pressure without inducing reflex tachycardia ${ }^{8}$ and the rate-pressure product, which is an index of myocardial oxygen demand, ${ }^{9}$ is therefore reduced. Captopril has been shown to reduce the rate-pressure product and myocardial ischaemia when the systolic blood pressure is greater than $100 \mathrm{~mm} \mathrm{Hg}$. ${ }^{10}$

Second, there is evidence in animals and in man that angiotensin converting enzyme inhibition can affect coronary blood flow. In laboratory animals with normal coronary arteries, coronary vascular resistance is increased by angiotensin $\mathrm{II}^{11}$ and the coronary vascular bed can convert angiotensin I to angiotensin II locally. Enalapril is an angiotensin antagonist in isolated coronary arteries ${ }^{12}$ and antagonises the coronary vasoconstrictor effect on angiotensin II. ${ }^{13}$ In one study in dogs given teprotide (an angiotensin converting enzyme inhibitor) coronary blood flow increased. ${ }^{14}$ When it was given to a group of patients who did not have significant coronary artery disease, teprotide improved coronary artery blood flow in some patients and it was suggested that the renin angiotensin inhibition may have affected the regulation of coronary flow. ${ }^{15}$

Third, there is evidence in man that prostacyclin may be involved in the control of coronary artery blood flow. ${ }^{16}$ The evidence that angiotensin converting enzyme inhibition may affect prostaglandin synthesis is only indirect. The antihypertensive effect of captopril is attenuated by indomethacin, a prostaglandin synthesis inhibitor. A similar role for enalapril has not yet been found in man.

The open trial of captopril in coronary artery disease showed significant improvement in ST segment depression during an exercise test after 48 hours' treatment. ${ }^{17}$ Other clinical studies of angiotensin converting enzyme inhibition in ischaemic heart disease have focused on patients with additional hypertension or heart failure. In one study of eight patients with hypertension and stable angina, there was no improvement or deterioration in symptoms or global myocardial metabolism. ${ }^{18}$ In an open study of $\alpha$ methyldopa versus captopril in 12 hypertensive 
patients with coronary artery disease, both drugs had the same antihypertensive effect, but captopril was associated with a significant improvement in ST segment depression on exercise. ${ }^{19}$

More recently, the active metabolite of enalapril (enalaprilat) has been used intravenously in 14 patients with heart failure, eight of whom had ischaemic heart disease..$^{20}$ In these patients there was a significant but transient reduction in myocardial oxygen extraction and an increase in coronary sinus oxygen saturation, suggesting coronary artery vasodilatation. In three of the patients with ischaemic heart disease there was also amelioration of abnormal myocardial lactate production, and it was proposed that this represented a reduction in myocardial ischaemia.

Drugs that act as vasodilators may also have the potential to make myocardial ischaemia worse. ${ }^{172122}$ The reduction in the rate-pressure product and hence myocardial oxygen demand has been significantly correlated with a reduction in coronary sinus blood flow in patients with heart failure..$^{23}$ In another study changes in coronary sinus flow paralleled changes in perfusion pressure. ${ }^{24}$ In a study of heart failure secondary to ischaemic heart disease, captopril did not improve coronary artery blood flow and it was noted that despite improved left ventricular function and reduction in the metabolic cost, myocardial ischaemia could be precipitated in some patients. ${ }^{25}$ Thus reduction in oxygen supply to the myocardium may outstrip reduction in oxygen demand obtained from improvement in left ventricular function and hence precipitate worse myocardial ischaemia. Such a mechanism in our patients remains speculative because the site and severity of coronary artery stenoses and the relation between the changes in perfusion pressure and coronary blood flow were not measured. In the presence of a severe fixed stenosis where there may be little coronary reserve, vasodilators may divert blood away from the ischaemic myocardium to non-ischaemic zones. Such a mechanism of coronary steal has been shown experimentally with arteriolar vasodilator $\mathrm{s}^{26}$ and in man. ${ }^{17}$

In conclusion, in a double blind, crossover, randomised study of enalapril versus placebo in normotensive patients with chronic stable angina, we found that enalapril tended to reduce myocardial ischaemia in the group; this may be clinically important but larger studies are needed before definitive conclusions can be drawn. Four of the 12 patients showed a considerable improvement but two became worse. From the available clinical data it is not possible to predict in advance which patients will benefit or deteriorate.

Ischaemic heart disease is often the underlying
Gibbs, Crean, Mockus, Wright, Sutton, Fox

cause of heart failure. Although myocardial ischaemia may be less important in patients with chronic heart failure than in patients with normal ventricular function, the beneficial effects of angiotensin converting enzyme inhibitors in heart failure may be offset if myocardial ischaemia is made worse. These drugs should be used, therefore, with caution in heart failure caused by ischaemic heart disease.

We thank Merck, Sharp and Dohme for supplies of enalapril and placebo.

\section{References}

1 Creager MA, Massie BM, Faxon DP, et al. Acute and long-term effects of enalapril on the cardiovascular response to exercise and exercise tolerance in patients with congestive heart failure. J Am Coll Cardiol 1985;6:163-70.

2 Hodsman GP, Zabludowski JR, Zoccali C, Fraser R, Morton JJ, Murray GD. Enalapril (MK 421) and its lysine analogue (MK 521): a comparison of acute and chronic effects on blood pressure, renin-angiotensin system and sodium excretion in normal man. $B r J$ Clin Pharmacol 1984;17:233-41.

3 Kohlmann O Jr, Bresnahan M, Gavras $\mathrm{H}$. Central and peripheral indices of sympathetic activity after blood pressure lowering with enalapril $(M K-421)$ or hydralazine in normotensive rats. Hypertension 1984;6(suppl 1):I-1-I-6.

4 MacGregor CA, Markandu ND, Bayliss J, Roulston JE, Squires M, Morton JJ. Non-sulfhydryl containing angiotensin converting enzyme inhibition (MK 421): evidence for a role of renin system in normotensive subjects. $\mathrm{Br}$ Med J 1981;283:401-3.

5 Bruce RA. Methods of exercise testing. Step test, bicycle, treadmill, isometrics. Am J Cardiol 1974; 33:715-20.

6 Biollaz J, Schellung JL, Jacot des Combes B, et al. Enalapril maleate and a lysine analogue (MK 521) in normal volunteers: relationship between plasma drug levels and the renin angiotensin system. $\mathrm{Br} J \mathrm{Clin}$ Pharmacol 1982;14:363-8.

7 Vlassis PH, Larijani GE, Conner DP, Ferguson RK. Enalapril, a non-sulfhydryl angiotensin converting enzyme inhibitor. Clin Pharm 1985;4:27-40.

8 Brunner DB, Desponds G, Biollaz J, Keller I, Ferber F. Effect of a new angiotensin converting enzyme inhibitor MK 421 and its lysine analogue on the components of the renin system in healthy subjects. Br J Clin Pharmacol 1981;11:461-7.

9 Graham TP Jr, Coyell JW, Sonnenblick EH, Ross J Jr, Braunwald E. Control of myocardial oxygen consumption: relative importance of contractile state and tension development. J Clin Invest 1968;47:375-85.

10 Daly P, Mettauer B, Rouleau JL, Cousineau D, Burgess JH. Lack of reflex increase in myocardial sympathetic tone after captopril: potential antianginal effect. Circulation 1985;71:317-25.

11 Fauter NO, Holmes JC. Coronary and myocardial 
actions of angiotensin. Circ Res 1964;14:191-201.

12 Lefer AM, Peck RC. Cardioprotective effects of enalapril in acute myocardial ischemia. Pharmacology 1984;29:61-9.

13 Lefer DJ, Lefer AM. Coronary vascular actions of the converting enzyme inhibitor enalapril. Proc Soc Exp Biol Med 1984;175:211-4.

14 Michel JB, Dussaule JC, Alhenc-Gelas F, Corvol P, Menard J. Can inhibition of the renin-angiotensin system have a cardioprotective effect? $J$ Cardiovasc Pharmacol 1985;7:575-9.

15 Faxon DP, Creager MA, Halperin JL, Sussman HF, Gavras H, Ryan TJ. The effect of angiotensin converting enzyme inhibition on coronary blood flow and hemodynamics in patients without coronary artery disease. Int J Cardiol 1982;2:251-62.

16 Wallis JB, Borer JS, Moses JW, Laragh JH. The reninangiotensin system. A primary factor in the control of coronary flow? Int J Cardiol 1982;2:263-5.

17 Tardieu A, Virot P, Vandroux JC, et al. Effects of captopril on myocardial perfusion in patients with coronary insufficiency: evaluation by the exercise test and quantitative myocardial tomoscintigraphy using thallium-201. Postgrad Med J 1986;62:38-41.

18 Daly P, Rouleau JL, Cousineau D, Burgess JH. Acute effects of captopril on the coronary circulation of patients with hypertension and angina. Am J Med 1984;76:111-5.

19 Strozzi C, Coeco G, Portaluppi F, et al. Ergometric evaluation of the effects of captopril in hypertensive patients with stable angina. $J$ Hypertens 1985;3:
5147-8.

20 DeMarco T, Daly PA, Lui M, Kayser S, Parmley WW, Chatterjee K. Enalaprilat, a new parenteral angiotensin converting enzyme inhibitor: rapid changes in systemic and coronary hemodynamics and humoral profile in chronic heart failure. J Am Coll Cardiol 1987;9:1131-8.

21 Baker KM, Johns DW, Ayers CR, Carey RM. Ischemic cardiovascular complications concurrent with administration of captopril. A clinical note. Hypertension 1980;2:73-4.

22 Chatterjee K, Rouleau JL, Parmley WW. Captopril in congestive heart failure: improved left ventricular function with decreased metabolic cost. Am Heart J 1982;104:1137-46.

23 Rouleau JL, Chatterjee K, Benge W, Parmley WW, Hiramatsu B. Alterations in left ventricular function and coronary hemodynamics with captopril, hydralazine and prazosin in chronic ischemic heart failure: a comparative study. Circulation 1982; 65:671-8.

24 Halperin JL, Faxon DP, Creager MA, et al. Coronary hemodynamic effects of angiotensin inhibition by captopril and teprotide in patients with congestive heart failure. Am J Cardiol 1982;50:967-72.

25 Chatterjee K, Rouleau J-L, Parmley WW. Haemodynamic and myocardial metabolic effects of captopril in chronic heart failure. Br Heart J 1982;47:233-8.

26 Maroko PR, Braunwald E. Modification of myocardial infarction size after coronary occlusion. Ann Intern Med 1973;79:720-33. 